\title{
Using blended learning to increase learner support and improve retention
}

Dr Gwyneth Hughes. Institute of Education, London

\section{Abstract}

Improving retention and identifying 'at risk' learners are high profile issues in Higher Education and a proposed solution is providing good learner support. Blending of online learning with classroom sessions offers the potential to use a virtual learning environment both to deliver learning activities and to support learners using a distance learning model. Online tracking can also help to target 'at risk' learners quickly. In an action research project to improve retention, a blended module with proactive tutor support was compared both with a previous cohort of the module, and with similar classroom-only modules where there was no focus on learner support. Learners were also interviewed and the tutor kept records of the learner contact time. The resulting improved coursework submission rate was attributed to learner motivation as a result of peer and tutor support. The total teaching time was no greater in this model, although the workload distribution changed and the tutor needed to be highly skilled in e-learning. 


\section{Introduction}

The widening of access to Higher Education has resulted in the issue of retention moving to the top of the agenda for many Universities. In the UK, the publication and benchmarking of retention statistics has provided a drive to address the issue urgently, especially for those institutions that have significant non-completion rates. While it is acknowledged that students from poorer backgrounds are more likely to withdraw from a course, it is less clear what is being done, or could be done, to improve the situation without compromising academic standards. Research on retention of campus-based students is often inadequate, and there is awareness of the need to investigate the causes of student withdrawal and the means to improve retention (Longden, 2002). The increasing use of online, open and distance learning adds to the unease over retention as there is evidence that attrition rates may be higher with these modes of delivery compared to campus delivery (Simpson, 2003). But, because distance learning providers have been more attuned to retention issues, there are numerous lessons learned here which are of relevance to retention on campus (Tait, 2004). One of these concerns the application of effective learner support.

This paper documents an action research project which aimed to improve retention at the module level through blending e-learning with classroom teaching and using the consequent reduction in face-to-face contact time to increase tutor support and target 'at risk' learners. In the first sections the lessons learnt from retention issues in distance learning and literature on the advantages and disadvantages of e-learning are discussed. In the next section, the paper explains how a method for targeting and supporting 'at risk' learners was applied to a third year undergraduate module which blended classroom sessions with online study. The retention on this module was compared to other similar modules where there was no intervention. In the penultimate sections, the results of the study are discussed. The paper concludes that blended learning with increased support and visible tutor monitoring can improve module retention by motivating learners to complete 
coursework on time. Contrary to popular perception, blended learning did not necessarily increase tutor workload.

\section{Retention issues in Distance Learning}

There have been several studies, mainly in the distance learning literature, which identify the key reasons why student leave their studies and predict which students are most likely to drop out. Reasons cited for leaving include those relating to personal resilience, personal identity factors, support networks as well as finding the course badly presented, poorly supported or too difficult. From these studies several theories on the causes of withdrawal have emerged.

The theories tend to fall into one of two categories: the integration approach and the motivation approach (Simpson, 2003). Integration considers the social and academic 'fit' between the learner and the institution and academic life. Feelings of isolation are well documented in distance learning and even in universities with a diverse student intake, those from non-traditional backgrounds can feel that they do not belong (Read et al, 2003). Increasing student engagement with tutors and peers can improve this sense of 'belonging' (Yorke, 2004). Meanwhile, the motivation approach puts more emphasis on individual motivation to succeed and the factors which might affect this such as choice of course, finance, employment prospects, personality, life circumstance and cognitive abilities (Christie et al, 2004). There is general agreement that reasons for withdrawal are likely to be complex with more than one cause affecting retention.

Different student retention issues occur at different stages in a course. Students may not complete enrolment, they can leave during the course itself to change course or they can leave the institution altogether (Simpson, 2003, 2004). Some of the student withdrawal is unavoidable but some could be prevented. Simpson describes a number of ways students can leave a course at the module level: they can actively withdraw, or passively withdraw by not submitting assignments or by failing assignments. This article is only concerned with the duration of the teaching at the module level and focuses 
on those who do not complete a module either through non-submission of assessments or failure as these are potentially areas where improvements could be made. It does not cover retrieval of students who fail and it is less concerned with institutional retention issues such as creating a sense of belonging to the wider social and academic culture.

Statistical studies at the Open University (Simpson, 2003) have also identified which students are most 'at risk' of withdrawal. Issues such as age, gender, previous qualification and social class/occupation are predictors of likelihood of retention with mature students (under 50), women, and those with higher qualifications and professional occupations being more likely to complete. However, such statistics need to be interpreted with caution as is discussed in the next section.

\section{'At Risk' Learners and Support}

There are two approaches to supporting 'at risk' learners. Identifying and targeting at risk learners and then offering additional support before a programme of study runs is one approach to improving retention. The second approach is to support learners during their course. The advantages and disadvantages of each approach are discussed below.

Examples of the first approach, the pre-course support method, indicate that results can be good. A retention scheme targeted at risk learners through tutor referrals at Kent University in 2001 and provided them with a summer school of support and skills development (Sellers \& Van der Velden, 2003). Students who participated had a retention of $97 \%$ on their studies overall.

However, the distinguishing and categorising of 'at risk' students is problematic. Basing risk on external factors such as previous performance, or expectations based on gender, class, ethnicity, age etc. may incorrectly 'label' some learners as disadvantaged while missing others and can reinforce prejudiced assumptions about certain groupings. Hughes and Lewis (2003) 
argue that it is more accurate to view being 'at risk' as something a learner becomes during the course of study: it is a temporary position into which a learner could move in and out. For example, a learner may start a course with no problems, but become 'at risk' either because of changes in personal external circumstance or because of dissatisfaction with the course. Others may bring with them ongoing difficulties which have not been fully resolved.

Intervention and alleviation of a learner's problem during a period of study could help avoid missing the needs of some learners and further promoting negative labelling of groups of others. In this second approach, tutors identify and follow up students who are not participating or submitting assignments while the course or module runs with the aim of supporting those in need. Distance learning tutors are often encouraged to take this approach (Tait, 2003). However, the UK Open University has found that tutors were easily disheartened by the time taken in chasing up students and the seemingly low success rate in retaining such students. But, they may not realise that there is a limit to the improvement good tutoring can make and that even a modest increase in retention is financially very beneficial for the institution (Simpson, 2003). Despite the difficulty in demonstrating the success of good tutor support, it is generally agreed that time spent on supporting at risk students is worthwhile and may even have a greater effect on retention than teaching ability.

Tutors for campus-based courses are expected to be reactive rather than proactive in dealing with student problems and chasing up non-attendees may be a lengthy process. Institutionally provided pastoral and skills support may also be limited because lecturers are not proactive in referrals. In addition, delivery of 'content' through lectures is not an efficient use of an academic's time (Bligh, 2001; Yorke, 2002) and lecture attendance perpetuates the myth of passive learning. Increasing blending of formal teaching with online selfstudy can shift the lecturer role away from delivery towards facilitation of learning and free up lecturer's time for learner support and referral that is more akin to good distance learning practice. A large scale US study of 
courses at community colleges which were designed in this manner demonstrated improvements in pass rates and reduction in withdrawal rates of disadvantaged students (Twigg, 2004).

In an online component of a campus-based course where the tutor spends facilitation time identifying and supporting the weaker learners, a tracking system in a Virtual Learning Environment (VLE) can be useful. It provides details of who has logged in, and when, and can be used as an early warning mechanism for non-engagement. The advantage of using tracking is that it enables a tutor to be quickly alerted to non-engagement, without having to scan through possibility unreliable registers for missing names, before the requirement for any submission of formative assessment. When such tracking is part of the online facilitation role, chasing up students is less likely to be perceived as a burden.

Learners with busy lives have little time to support each other face-to-face but online they too might find more opportunity to support each other both academically and through social interaction (Yorke, 2004).

Blended learning in which a campus course is partly delivered online could also improve retention though enabling students to learn more deeply (Fox \& MacKeogh, 2003) as time spent attending lectures is replaced by accessing online content and collaborative learning between peers. Online there can be a blurring between the collaborative learning processes and the tutor support processes (Thorpe, 2002) if the tutor facilitates learner to learner support as well as tutor to learner support.

Blended learning thus offers several inter-related ways of improving retention. The identification and monitoring of at risk learners while a course is running and intervening promptly is one way, but improving student learning and a sense of belonging are also potential benefits of blending. Nevertheless, online learning is not without its disadvantages. 


\section{Some Critiques of Online Learning}

A growing body of research supports the view that some socially constructed barriers to learning may disadvantage learners in online environments. Previous work (Hughes \& Lewis, 2003) demonstrated that in campus-based courses with online components, some learners were successful and found the experience positive. Another group of learners was also successful, but disliked the online experience mainly because of poorly designed online environments and lack of guidance and support from tutors on how to learn online. Students from a third group were similarly frustrated by the experience, but did not perform well. In the study these 'at risk' learners described combinations of factors such as dyslexia, English as an Additional Language, low self-esteem, weak ICT skills and heavy outside pressures which, in these particular learning environments, contributed to poor performance in online tasks such as asynchronous conferencing and online tests. The study suggested that improving online structuring of tasks would improve the experience of the dissatisfied achievers, but it would not necessarily improve the performance of all the low achievers who found that their learning difficulties were compounded by moving online.

Miller et al, 2000, and Selwyn and Gorard, 2003 also raise concerns regarding the widening participation agenda and how the use of technologies may exacerbate disadvantages of those from non-traditional backgrounds. They stress that such learners may need additional tutor support and guidance for learning how to learn online as well as technical support.

Successful blended learning will therefore need to balance carefully the advantages and disadvantages of online versus classroom experience.

\section{The study on improving retention using blended learning}

The discussion so far has suggested that replacing some campus-based attendance with online learning could release more time for tutor support and facilitating activity than in the lecture-based model of delivery and consequently improve the learning experience. To test this proposal the 
author of this paper worked with a module tutor of the final year of a degree in Education at a post-1992 UK university. Retention at the institution was low, hovering around the two thirds mark, and improving this figure was an institutional priority.

The study was loosely based on the principles of action research in as far as action research is concerned primarily with providing practical solutions to real situations (Reason \& Bradbury, 2004). When applied to the professional practice of education the purpose is "to create and extend theory, to illuminate and inform practice and to influence policy in an informed way" (Macpherson et al. 2004: 95). The main aim of this study was to propose and test a method for improving retention at the module level using readily available e-learning technologies.

The blended learning module under study ran three times with cohorts of 20 , 15 and 30 students respectively. The first time was prior to the action research and intervention was made for the second and third cohorts.

It was run by an experienced online tutor and was well designed according to current online learning research (Wallace, 2003), for example, through providing learners with regular collaborative tasks, formative assessment and feedback as well as informal/social interaction. Learners were all given an induction workshop to ensure they were comfortable in using the technology and two further face-to-face workshops as part of the blend. The carefully structured blended environment would be expected to reduce some of the confusion about how to learn online identified in previous studies. Assessment was by coursework including an essay and a portfolio and online participation was included in assessment criteria.

1.

2.

3. 
The tutor aimed for high retention through early targeting of potentially failing students and providing support to these individuals. She kept a list of learners who she considered to be at risk of non-completion and noted why. She initially identified students to be at risk if they were not logging in or communicating online regularly or if they did not complete formative assessment tasks. Students who made frequent requests for help, reported personal problems to the tutor or those were repeating the module after failing were also potentially at risk. If a student's problem was apparently resolved and they were engaging with the module, they were subsequently removed from the list for proactive support. For example, a few students had some initial technical difficulties but these were soon resolved so they would not continue to be at risk. This regular updating was to ensure that students were targeted only if there was some ongoing problem and not because of a previous label and to acknowledge that the 'at risk' category is inherently unstable.

In distance learning it is generally acknowledged that some $10 \%$ of learners will not need or want support (Rekkedal \& Qvist-Eriksen, 2003). Others will need support but may not ask for it. Therefore, in the blended module, tutor support was not only reactive, but also proactive, to recognise that some vulnerable learners may not have the confidence or awareness to request help.

Most of the tutor support took place in the virtual learning environment (VLE), WebCT where learner participation was visible. The support addressed difficulties with learning online as well as areas such as academic writing, time management, group work, library skill, technical skills etc. The tutor aimed to be positive and encouraged students to persevere while taking care not to reinforce any feelings of negativity that arise from failure (Cannon, 2003). Support also included the university's existing mechanism of referring students for help with study skills and student counselling, but in this case there was careful monitoring. The tutor made regular contact with at risk 
learners and monitored all students' progress using online tracking to amend and update this list as necessary. The tutor also encouraged all learners to gain learning support from peers with the aim of reducing tutor dependency.

The tutor kept a weekly log of all contact time activities including targeted support for at risk learners. The support was mainly online, not surprising given the blended delivery, but it also included a small amount of telephone and face-to-face support. The technology used for targeted support and time taken were recorded using a tutor log adapted from MacDonald \& McAteer (2003). The type of support (administrative, technical, motivational or academic) was also recorded. Administration concerned the rules of the institution; technical was mainly concerned with use of the VLE, motivational support included encouragement and dealing with emotional issues while academic support referred to supporting and planning of learning.

To measure the retention levels on this module, the examination board data was used. Such data should be accurate, but because of possible errors or delay in entering or deleting student records, there is no guarantee of complete objectivity in such statistical data (Reimann, 2004). The submission data as well as the combined failure/non-completion data were recorded at the first assessment board. This combined figure was defined as the total of students who had not passed plus who did not submit at the first examination board. Such students would be required to repeat assignments, resit the module or seek alternatives and thus have not been retained at this stage of the module. Students giving notification of withdrawal from the module or the university were not included in the statistics recorded for this study as they would be removed from the student record system.

A total of 19 students from both cohorts gave feedback via an email questionnaire or equivalent telephone interview.

In addition, the online messages sent by both students and the tutor were reviewed for further evidence of student dis/satisfaction and to assess the tutor's style of e-moderating and supporting students online. 
To compare how well learners fared on conventionally taught modules without any special intervention, examination board statistics were recorded from modules with similar student numbers, similar learner backgrounds, similar modes of assessment and in the same disciplinary area of study, but taught wholly on campus and without any targeted support strategy. One of these comparative modules was taught by the same tutor as the blended learning module and many of the students were the same. Statistical data from a previous cohort of students on the blended course where there was no targeting of at risk students was also recorded.

Concerns about learner support being time-consuming were addressed by the tutor keeping a weekly record of the total time spent teaching the blended module and the wholly classroom based module which she was teaching in parallel. The time taken for the record keeping was included in the teaching time for the modules but not the time spent on planning, discussing and writing up the research. Because of the inevitable unpredictability of this type of action research, it is not possible to control variables as one usually might for a comparative study so results need to be interpreted with this in mind.

\section{Findings and Discussion part 1: Learner Support and Retention}

\section{Overview of the blended module}

A review of the VLE showed that this was a well-facilitated module. Students received advice on technical matters, process, writing assignments as well as administrative, social and personal support. The tutor encouraged students to help each other even when she might need to intervene at a later stage.

There was evidence of technical and academic support between peers and of social interaction. Because of the peer support the tutor was not overwhelmed by individual requests for help and responded to these promptly. Face-to-face 
workshops were also used for learner support particularly concerning the assessments.

In retrospect the tutor was successful at identifying 'at risk' learners in that all those who either failed or did not submit were picked up at some stage during in the study. Out of a total of 17 at risk students identified in the two cohorts where the intervention took place, 11 passed and 6 did not pass/submit.

\section{Blended Module submission and pass rate of the targeted cohort compared to previous cohort on the same module}

The completion figures in table I show that there was a higher proportion of students submitting all their work in the targeted second and third cohorts of students than in the previous cohort. The second cohort had a particularly high success of $94 \%$ because only one student did not submit work. The third cohort was not as successful as the second, but nevertheless the submission rate was better than that of the cohort which had no intervention.

\section{TABLE I here}

There are numerous explanations for the improved retention, there could be differences in the student profile that are significant for small numbers and indeed the success of the second cohort could be partly attributed to the small size of the group. Other data below suggest that it is very possible that the improved learner support has had an effect on submission rates. 


\section{Blended module submission and pass rate compared to face-to-face modules in the same discipline at the same level of study}

The $94 \%$ submission rate for the blended course shown in table II is also favourable compared to other year 3 modules. The conventionally taught module which was taught by the same tutor (Module 2) had a lower submission rate of $78 \%$. This is only marginally better than two of the other face-to-face modules suggesting that the tutor was not exceptional in the conventional setting. When the incomplete submission and failure rates were combined, the blended module stood out as much better than all the face-to-face modules at $6 \%$ compared to $25 \%$ and higher. The failure rate was very low for all the modules taught by this tutor indicating that blended learning might be affecting the submission rate rather than attainment of the weaker students.

\section{TABLE II here}

Total numbers were much lower in the blended module than the others and this could be having a positive influence on retention. Therefore a third cohort was studied in which the student numbers were much more comparable. Table III again shows that again the blended module had a higher submission rate than the others and a similarly low failure/non-submission rate. This would suggest that the number of students on the module is not so significant and that it is the module design and teaching which improves retention.

\section{TABLE III here}

From the literature discussed earlier, improved submission rates on the blended modules with targeted support could be a result of more active learning, expert tutor facilitation and the targeting of 'at risk' learners, peer support or a combination of factors since all these are interrelated. Even 
taking part in the study itself could have made the tutor more 'support aware' and produced an effect. Student feedback provides some further insight.

\section{Student views and achievement: blended learning with good tutor support improves submission rates}

Both the non-targeted and at risk students from cohorts 2 and 3 were very positive about the tutor support they obtained on the module confirming that it was well facilitated. For some the visible tutor monitoring and checking up of progress was motivating. There was some evidence that the collaborative learning and peer support was also helpful. These points are discussed in turn below.

Firstly, feedback showed that many students found the tutor support motivating. One student (female student A) described the guidance from the tutor as:

"Constant guidance, outlining clearly the tasks set which helped focus my reading on the subject. Also tutor was readily available to answer the little questions that often, nobody asks in class."

She implied that in her previous experience this level of tutor support was not available and that this time tutor feedback was motivating.

"Yes, for the first time I was able to ask if my work (assignment) was going in the right direction, this was extremely motivating as although I do not know my grade yet, I was able to put all worries of 'am I writing completely the wrong thing' from my mind."

The online tutor support was highly praised by one moderately high achieving, part-time mature student:

"Absolutely $110 \%$. She was just brilliant. She was there when you need her but she wasn't leading us. She gave feedback after an activity but left us to 
our own devices as well. The instructions meant we knew exactly what we needed to achieve. We got just enough support and were not being controlled. We were left to learn and reflect". (female student E)

The 'at risk' students were equally positive about their experiences. An 'at risk' learner who passed explained how she had been guided and motivated by targeted support.

"..(the tutor) explaining the task to set you off in the right direction ... a private reply gives a boost when you need it". (female student $B$ )

Secondly, the tutor monitoring had a motivating effect for 'at risk' learners and encouraged them to complete their work. An 'at risk' (female student G) who passed stated:

"We're being watched all the time so we can't be work-shy. We could have done with it in the second year...we can't get to skive"

It might be presumed that students at this level would be self-motivated rather than motivated by fear of being caught out and ethical issues have been raised about tutor surveillance (Land \& Bayne, 2004). But, other students found the tutor monitoring motivating.

A confident male student $(\mathrm{H})$ admitted that he joined in activities more than he would with a classroom seminar:

"I bothered my backside more with online activities and made the deadlines".

But the workload was perceived as too heavy for some as one at risk learner (female student I) who was positive about the tutor support but did not complete the module stated:

"I flaked out towards the end as it was very intense". 
This is consistent with findings that some vulnerable learners are disadvantaged online and tutor support alone may not be sufficient to meet their needs.

Finally, the contribution of collaboration and peer support to improving learning and motivation discussed in the literature was less evident in this study. There were some typical reservations about working with peers online but also some positive feedback on peer support. A (male student $C$ ) commented that:

"It was a repetitive module ....and enthusiasm wanes but I enjoyed the first part with everyone pulling their weight."

and another:

"I enjoyed it more than other education units. You could read other people's work. I liked the debates, liked the challenge but got frustrated with some of the ridiculous questions from some students in the group who 'hooked' on to everyone else." (female student D)

The feedback suggest that it was mainly tutor presence through proactive tutor support, encouragement and monitoring which helped learners, particularly those who were targeted for support, to submit their work in time and thus improve module retention. Such support was provided during the online part of the course to a large extent. The comments are consistent with the previous evidence from the distance learning literature that good learner support improves module retention. But,

while the students viewed the online tutor as supportive and motivational, that is not to rule out the possibility that other differences between online and faceto-face such as deeper learning through peer collaboration and support were not significant and the reduced emphasis on peer support in the learner feedback could be due to lack of learner awareness of this possibility. 
Findings and Discussion part 2: Tutor Time for Blended Learning

Supporting students in this way did require the tutor to put in more time at the beginning of the module in comparison to face-to-face modules that she was teaching. The tutor found that her time was 'front-loaded' within the semester with the extra time committed in the early weeks being mainly used for supporting students with technical problems and in encouraging those who had never used a VLE to participate. The workload (not including marking of assignments) broke down across the semester as shown in Figure1 below. The peaks in hours shown in weeks 4 and 11 were due to the face-to-face workshops held during these weeks to support all students.

FIGURE 1 here 
It is worth noting that the bulk of the tutor support was for the whole class with the targeting of 'at risk' students taking up a relatively small amount of time. This is contrary to the lecturer views that 'chasing up' is too time-consuming reported in the distance learning literature.

Comparison between a face-to-face and the blended module in figure 2 below shows that the weekly teaching pattern was much more regular in the face-toface module.

\section{FIGURE 2 here}

There was consistency of this pattern between cohorts 2 and 3 indicating that, although the numbers are unlikely to be highly accurate, there are differences in workload distributions in blended and conventional teaching. However, the total teaching hours shown in table IV are comparable.

\section{TABLE IV here}

A typical workload allocation for teaching was three hours teaching plus two hours preparation per week with a total of 60 hours as being appropriate for teaching the module (this is not including the module leader's roles of administration or preparation of handbooks). Thus, the blended approach was well within the 60 hours allocated and comparable with the hours required to teach the face-to-face only module. Cohort 3 modules were all repeats of cohort 2 within a short time scale which could explain the reduced preparation time.

The study therefore supports the theory that shifting emphasis from content delivery to learner support is an efficient use of lecturers' time if it results in improving completion of coursework. 


\section{Conclusion}

The results from this action research suggest that a combination of welldesigned and supported blended learning with proactive help and encouragement for 'at risk' learners can improve coursework submission and therefore module retention without increasing overall teaching time. The online environment facilitated visible tutor support and 'at risk' learners could be monitored with the aim of encouraging coursework completion. There was some evidence that peer support was also motivating. However, it should be emphasised that, as well having experience with the software, the tutor needs skills in designing co-operative learning online and facilitating peer-to-peer support without being intrusive. Less experienced staff would not be expected to gain such impressive results without further training or an expert mentor. Indeed without the expertise this could be a high risk approach.

Blended learning combined with proactive learner support could be applied to any discipline. Action research has been successful in improving retention in this case, but using this methodology it is not possible to pinpoint exact causes and effects. Retention is a complex issue and a solution for one module or one disciplinary area may not be the best solution for another. The blended module was part of an Education course and one could argue that the learners were motivated to explore new learning approaches online. Further questions to raise will be whether or not blending plus targeted learner support can succeed in improving retention for other disciplines, levels or modes of assessment and further studies are already underway. 


\section{References}

Bligh, D. (2001) What's the use of Lectures? (Bristol, Intellect).

Cannon, D. (2002) Learning to Fail: Learning to Recover, in: M. Peelo \& T. Wareham (Eds) Failing Students in Higher Education (Buckingham, SRHE and Open University Press).

Christie, H., Munro, M. \& Fisher, T. (2004) Leaving university early: exploring the differences between continuing and non-continuing students, Studies in Higher Education, 29,5 pp. 617-636

Fox, S. \& MacKeogh, K. (2003) Can eLearning Promote Higher-order Learning Without Tutor Overload? Open Learning, 18,2, pp. 121-134.

Hughes, G and Lewis, L (2003) Who are successful online learners? Exploring the different learner identities produced in virtual learning environments, in: J. Cook and D. McConnell (Eds) Communities of Practice. Research Proceedings of the 10th Association for Learning Technology Conference (ALT-C 2003) (The University of Sheffield and Sheffield Hallam University, UK)

Land, R. \& Bayne, S. (2004) Screen or monitor: issues of surveillance and disciplinary power in online learning environments, in: R. Land. \& S. Bayne (Eds) Education in Cyberspace (London, RoutledgeFalmer).

Longden, B. (2002) Retention rates - renewed interest but whose interest is being served?, Research Papers in Education, 17, 1, pp. 3-29.

MacDonald, J. \& McAteer, E. (2003) New Approaches to Supporting Students: strategies for blended learning in distance and campus based environments, Journal of Educational Media, 28,2-3, pp.129-146. 
Macpherson, I., Brooker, R., Aspland, T., \& Cuskelly, E. (2004) Constructing a territory for professional practice research, Action research, 2,1, pp. 89-106.

Miller, N., Kennedy, H. \& Leung, L. (2000) Tending to the tamagotchi: rhetoric and reality in the use of new technologies for distance learning, in: S. Wyatt, F. Henwood, N. Miller \& P. Senker (Eds) Technology and In/equality. Questioning the information society (London, Routledge).

Read, B., Archer, L. \& Leathwood, C. (2003) Challenging Cultures? Student Conceptions of 'Belonging' and 'Isolation' at a Post-1992 University, Studies in Higher Education, 28,3, pp. 261-277.

Reason, P. \& Bradbury, H. (2004) Action Research Purpose, Vision, Mission, Action research, 2,1, (Journal launch statement).

Reimann, N. (2004) Calculating Non-completion Rates for Modules on Institution-wide Language Programmes: some observations on the nature of seemingly objective figures, Journal of Further \& Higher Education, 28,2, pp. 139-152.

Rekkedal, T. \& Qvist-Eriksen, S. (2003) Internet Based E-learning, Pedagogy and Support Systems, in: H. Fritsch (Ed) The role of student support services in e-learning (Hagen, FernUniversitat ZIFF Papiere 121).

Sellers, J. \& Van der Velden, G. (2003) Supporting Student Retention, LTSN Generic Centre Continuing Professional Development series No. 5 www.ltsn.ac.uk [Accessed 20.2.04].

Selwyn, N. \& Gorard, S. (2003). Reality bytes: examining the rhetoric or widening educational participation via ICT, British Journal of Educational Technology, 34,2, pp.169-181. 
Simpson, O. (2003) Student Retention in Online, Open and Distance Learning (London, Kogan Page).

Simpson, O. (2004) The impact on retention of interventions to support distance learning students, Open Learning, 19,1, pp. 79-95.

Tait, J. (2004) The tutor/facilitator role in student retention, Open Learning 19,1, pp. 97-109.

Thorpe, M. (2002) Rethinking Learner Support: the challenge of collaborative online learning, Open learning, 17,2, pp.105-119.

Twigg, C. (2004) Using asynchronous learning in redesign: reaching and retaining the at-risk student, Journal of Asynchronous Learning, 8,1, pp. 7-15.

Wallace, R. (2003) Online Learning in Higher Education: a review of research on interactions among teachers and students, Education, Communication \& Information, 3,2, pp. 241-280.

Yorke, M. (2002) Academic Failure: a Retrospective View from Noncompleting Students, in: M. Peelo \& T. Wareham (Eds) Failing Students in Higher Education (Buckingham, SRHE and Open University Press).

Yorke, M. (2004) Retention, persistence and success in on-campus higher education, and their enhancement in open and distance learning, Open Learning, 19,1, pp. 19-32. 


\begin{tabular}{|c|c|c|c|}
\hline & $\begin{array}{c}\text { Non-targeted } \\
\left(1^{\text {st }}\right) \text { Cohort } \\
\mathrm{n}=20\end{array}$ & $\begin{array}{c}\text { Targeted }\left(2^{\text {nd }}\right) \\
\text { Cohort }\end{array}$ & $\begin{array}{c}\text { Targeted (3rd) } \\
\text { Cohort }\end{array}$ \\
\hline $\begin{array}{c}\text { Percentage } \\
\text { students } \\
\text { submitting all } \\
\text { work }\end{array}$ & $75 \%$ & $94 \%$ & $\mathrm{n}=30$ \\
\hline $\begin{array}{c}\text { Total } \\
\text { fail/incomplete } \\
\text { submission }\end{array}$ & $25 \%$ & $6 \%$ & $15 \%$ \\
\hline
\end{tabular}

TABLE I: Comparison of retention of the targeted blended learning cohorts of students with the initial non-targeted cohort 


\begin{tabular}{|c|c|c|c|c|c|}
\hline & $\begin{array}{c}\text { Blended } \\
\text { Module } \\
\left(2^{\text {nd }}\right. \\
\text { cohort }) \\
\mathrm{n}=15\end{array}$ & $\begin{array}{c}\text { Face-to- } \\
\text { face } \\
\text { Module 1 } \\
\mathrm{n}=75\end{array}$ & $\begin{array}{c}\text { Face-to- } \\
\text { face } \\
\text { Module 2* } \\
\mathrm{n}=49\end{array}$ & $\begin{array}{c}\text { Face-to- } \\
\text { face } \\
\text { Module 3 } \\
\mathrm{n}=27\end{array}$ & $\begin{array}{c}\text { Face-to- } \\
\text { face } \\
\text { Module 4 } \\
\mathrm{n}=50\end{array}$ \\
\hline $\begin{array}{c}\text { Percentage } \\
\text { students } \\
\text { submitting all } \\
\text { work }\end{array}$ & $94 \%$ & $73 \%$ & $78 \%$ & $93 \%$ & $72 \%$ \\
\hline $\begin{array}{c}\text { Incomplete } \\
\text { submission }\end{array}$ & $6 \%$ & $27 \%$ & $22 \%$ & $7 \%$ & $28 \%$ \\
\hline Fail & $0 \%$ & $28 \%$ & $3 \%$ & $19 \%$ & $20 \%$ \\
\hline $\begin{array}{c}\text { Total } \\
\text { fail/incomplete } \\
\text { submission }\end{array}$ & $6 \%$ & $55 \%$ & $25 \%$ & $26 \%$ & $48 \%$ \\
\hline
\end{tabular}

*taught by same tutor as Blended module

TABLE II: Comparison of retention of cohort 2 with classroom-only modules in the same discipline 


\begin{tabular}{|c|c|c|c|c|}
\hline & $\begin{array}{c}\text { Blended } \\
\text { Module (3rd } \\
\text { cohort) } \\
\mathrm{n}=30\end{array}$ & $\begin{array}{c}\text { Face-to- } \\
\text { face } \\
\text { Module 1 } \\
\mathrm{n}=25\end{array}$ & $\begin{array}{c}\text { Face-to- } \\
\text { face } \\
\text { Module 2* } \\
\mathrm{n}=28\end{array}$ & ** \\
\hline $\begin{array}{c}\text { Percentage } \\
\text { students } \\
\text { submitting all } \\
\text { work }\end{array}$ & $87 \%$ & $60 \%$ & $64 \%$ & \\
\hline $\begin{array}{c}\text { Incomplete } \\
\text { submission }\end{array}$ & $13 \%$ & $40 \%$ & $33 \%$ & \\
\hline Fail & $4 \%$ & $0 \%$ & $3 \%$ & \\
\hline $\begin{array}{c}\text { Total } \\
\text { fail/incomplete } \\
\text { submission }\end{array}$ & $17 \%$ & $40 \%$ & $36 \%$ & \\
\hline
\end{tabular}

** Note that Modules 3 and 4 were not repeated and run in parallel to the blended module and so are not included here.

TABLE III: Comparison of retention of cohort 3 with classroom-only modules in the same discipline 


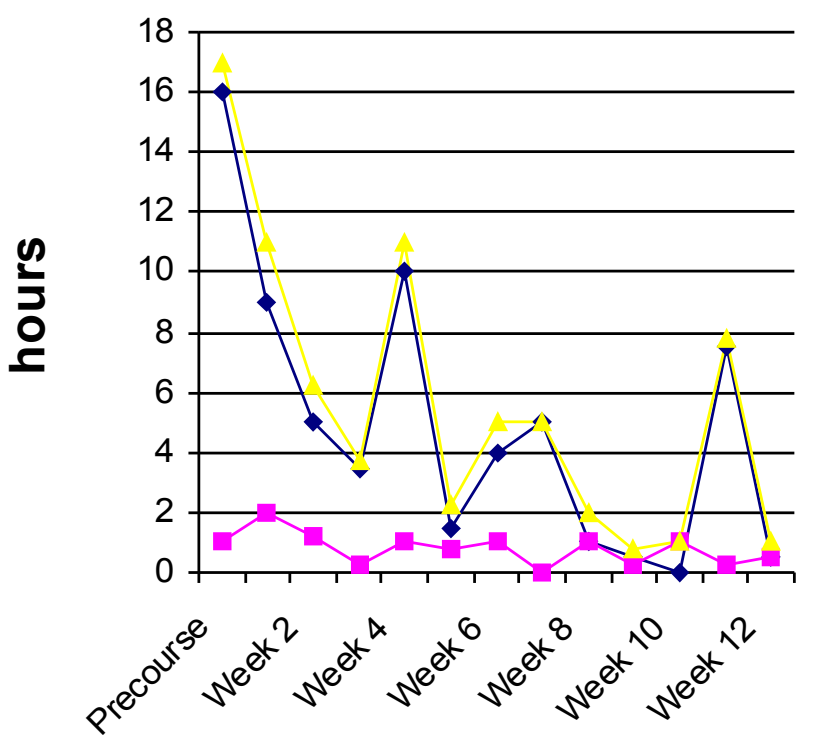

$\multimap$ Whole class teaching

$\rightarrow-$ Targeting

Total hours

FIGURE 1: Tutor hours by week broken down by whole class teaching and support and hours spent targeting 'at risk' students (cohort 2) 


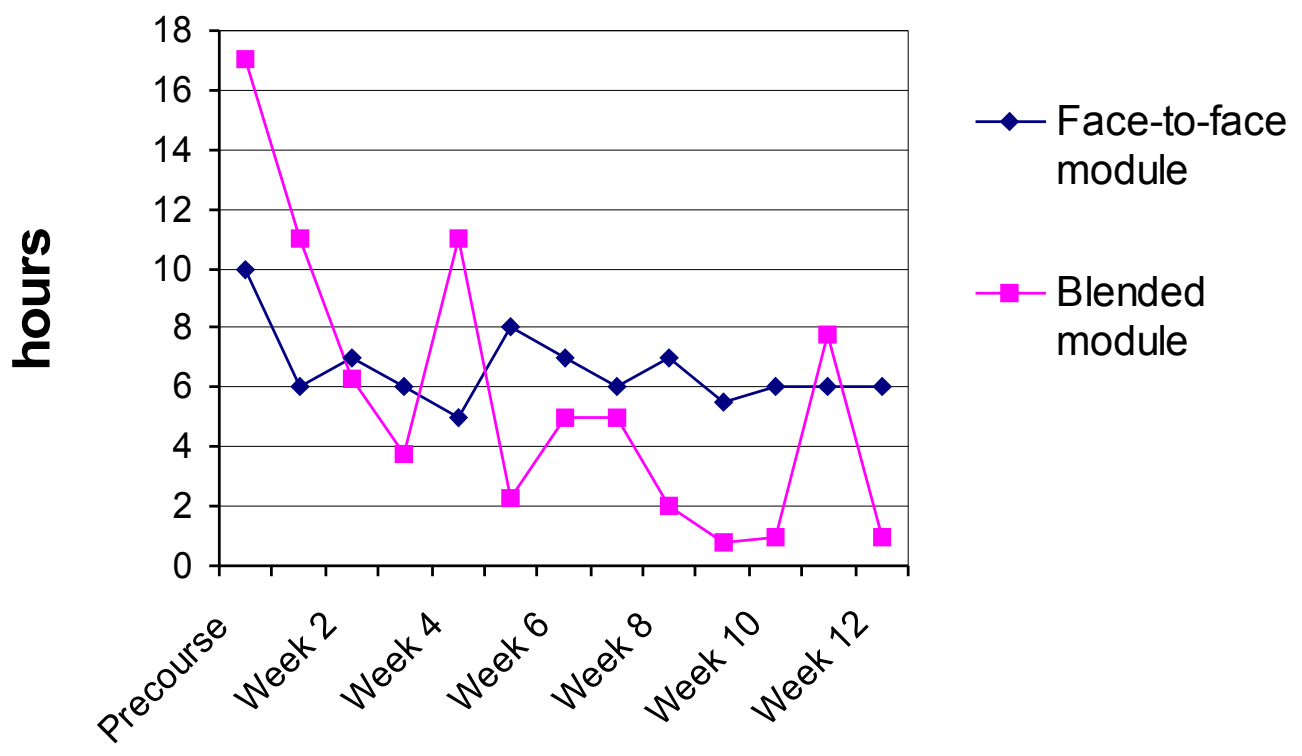

FIGURE 2: Online module tutor hours (cohort 2) compared to a face-toface module over the same time period 


\begin{tabular}{|l|l|l|l|l|l|l|}
\hline & \multicolumn{3}{|l|}{ Cohort 2 } & \multicolumn{2}{l|}{ Cohort 3 } & \multicolumn{2}{l|}{} \\
\cline { 2 - 7 } & $\begin{array}{l}\text { Preparation } \\
\text { hours }\end{array}$ & $\begin{array}{l}\text { Teaching } \\
\text { Hours }\end{array}$ & $\begin{array}{l}\text { Total } \\
\text { hours }\end{array}$ & $\begin{array}{l}\text { Preparation } \\
\text { hours }\end{array}$ & $\begin{array}{l}\text { Teaching } \\
\text { Hours }\end{array}$ & $\begin{array}{l}\text { Total } \\
\text { hours }\end{array}$ \\
\hline $\begin{array}{l}\text { Blended } \\
\text { module }\end{array}$ & 17 & 57 & 74 & 4 & 57 & 61 \\
\hline $\begin{array}{l}\text { Face-to- } \\
\text { face } \\
\text { module }\end{array}$ & 10 & 75.5 & 85.5 & 4 & 58.5 & 62.5 \\
\hline
\end{tabular}

TABLE IV: Comparison of total hours spend in preparation for and teaching of blended and face-to-face modules 